\title{
Ulceration of the cornea in rheumatoid arthritis
}

\author{
MALCOLM I. V. JAYSON, ${ }^{1}$ AND DAVID L. EASTY ${ }^{2}$
}

From the Department of Medicine, University of Bristol, and the Royal National Hospital for Rheumat Diseases, Bath, ${ }^{1}$ and Bristol Eye Hospital, ${ }^{2}$ Bristol

SUMMARY Five patients with melting of the cornea in association with rheumatoid arthritis are described. The arthritis was often inactive and without systemic manifestations, in contrast to that seen in association with scleritis. In 3 there was evidence of reduced tear formation, but in nong was tear production absent. In 3 patients the lesions healed during treatment with azathioprine oge penicillamine.

Scleritis is a well recognized complication of rheumatoid arthritis (Jayson and Jones, 1971; McGavin et al., 1976; Watson and Hayreh, 1976). Sometimes inflammation from the sclera can spread into and involve adjacent cornea (sclerokeratitis); this may be associated with marginal thinning. However, disease of the cornea can occur alone without involvement of the sclera with little or no inflammatory change. Occasionally marginal thinning may be gross with corneal melting (keratolysis) which may proceed to perforation. The association of keratolysis with rheumatoid arthritis is well recognized by ophthalmologists (Brown and Grayson, 1968; Watson, 1975), but not by rheumatologists and no attention has been paid to the rheumatological features of the disease. We present data on 5 patients with marginal gutter ulcers of the cornea in association with rheumatoid arthritis.

\section{Case reports}

CASE 1

This woman had a 22-year history of rheumatoid arthritis starting in the fingers and wrists and later affecting the feet, ankles, and knees. She had been maintained on methylprednisolone $4 \mathrm{mg}$ a day for several years and a variety of anti-inflammatory drugs. By November 1975 she showed gross changes of advanced inactive rheumatoid arthritis affecting the proximal interphalangeal (PIP), metacarpophalangeal (MCP), and wrist joints, both shoulders, the metatarsophalangeal (MTP) joints of both feet, and both knees with fixed flexion deformities. There was no synovial thickening nor increased temperature

Accepted for publication March 3, 1977

Correspondence to Prof. M. I. V. Jayson, Department of Rheumatology, University of Manchester, Hope Hospital, Eccles Old Road, Salford, Manchester M6 8HD over any of the joints. Investigations showed 8 normal plasma viscosity, haemoglobin, and white blood count. Rose-Waaler and latex tests were negative, as were tests for antinuclear factor and other autoantibodies; no LE cells were founळ $X$-rays showed gross changes of rheumatoid arthritis.

In November 1974 she had been seen elsewhere with a complaint of dryness of the eyes, but not the mouth, and was given artificial tears. In Januar 1975 the corrected visual acuity was $6 / 60$ in the right eye and $6 / 36$ in the left; there was some sore: ness and irritation of both eyes, and periphera corneal thinning was noted, more marked on the right than the left. There was minimal evidence of inflammation with only slight hyperaemia of the sclera in the area adjacent to the cornea. In February 1975 the cornea perforated (Fig. 1) and was repaireg with a peripheral annular corneoscleral graft. Thẹe initial result was satisfactory but 2 weeks aft surgery the donor tissue became infiltrated wi inflammatory cells. It was thought that the appeae ance was consistent with an acute homograft reaction. In order to keep the donor tissue position, a conjunctival pedicle flap was fashioned and sutured over the grafted area. Further melting of central corneal tissue occurred at the edge of the conjunctival flap.

Similar corneal thinning developed in the left exe (Fig. 2) which failed to respond to intensive loca therapy including subconjunctival heparin but nE steroids. Eventually the cornea perforated with prolapse of the iris. In April 1975 this was repaired by mobilizing a flap from the adjacent sclera and overlaying this with a conjunctival bridge flap. In November 1975 the scleral flap retracted anil perforation seemed imminent. During these surgic\$1 procedures, peripheral corneal melting progress 
remorselessly in both eyes despite 2-hourly treatment with 1-cysteine eye drops.

Although the rheumatoid arthritis seemed completely inactive, she was started on azathioprine $50 \mathrm{mg}$ bd $(2.5 \mathrm{mg} / \mathrm{kg})$ and her progress was closely followed by slit lamp examinations. Over the succeeding weeks the melting ceased, and by June 1976 re-epithelialization and stromal regeneration had occurred over the previously repaired iris prolapse in the left cornea (Fig. 3). The final visual acuity in the right eye was no better than 'counting fingers', but with the left eye an acuity of $6 / 12$ and N5 was achieved.

\section{CASE 2}

A less severe example of marginal corneal ulceration occurred in this 75-year-old man with a 2-year history of rheumatoid arthritis affecting principally the PIP and MCP joints of both hands and both wrists. Plasma viscosity was raised at $2 \cdot 42 \mathrm{cP}$, haemoglobin $12.5 \mathrm{~g} / \mathrm{dl}$, and white cell count $8 \cdot 3 \times 10^{9} / 1$. Rhematoid factor was present in a titre
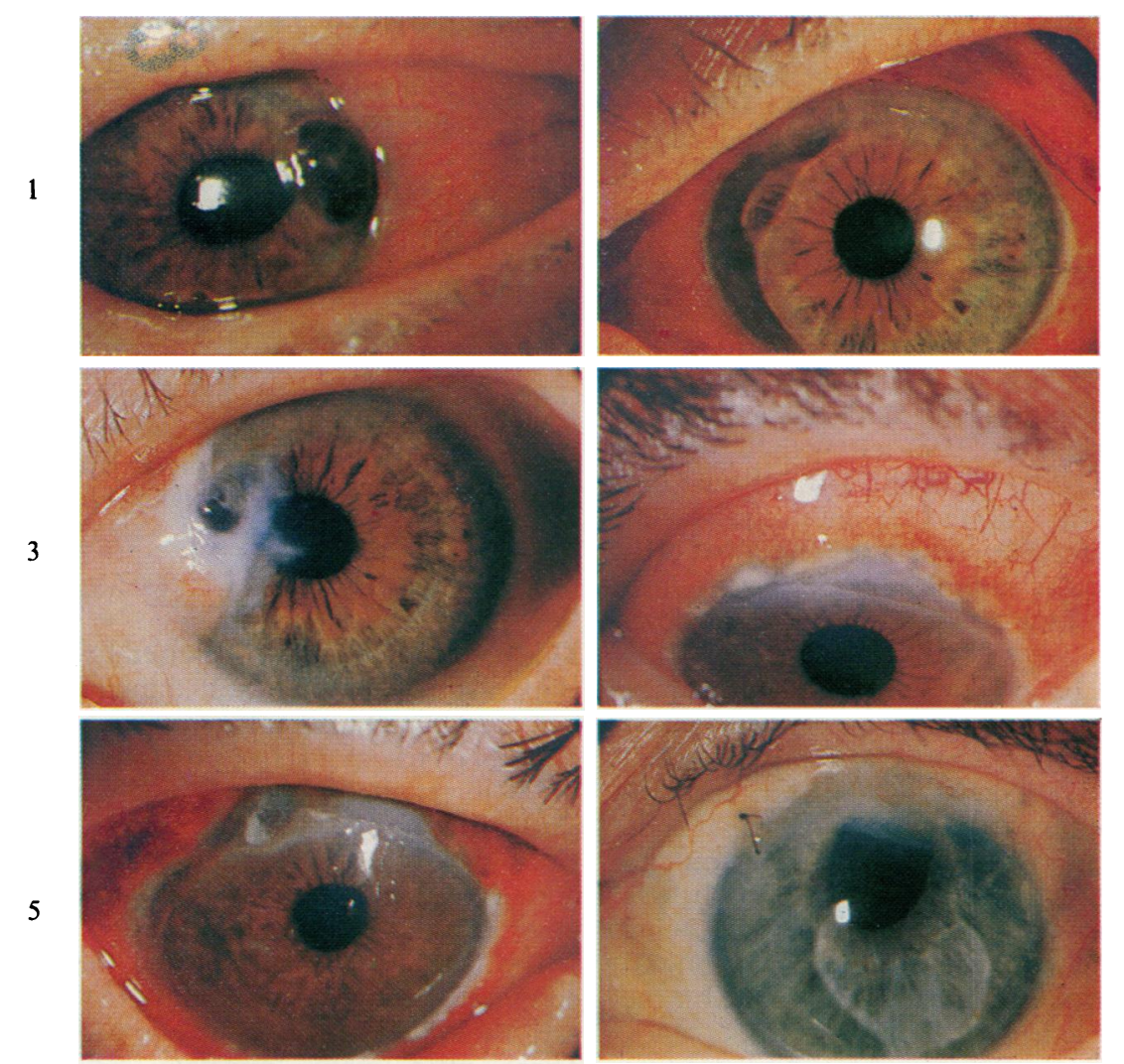

Fig. 1 Case 1. Right cornea, showing prolapsed iris through a perforated marginal ulcer. An annular corneoscleral graft was performed.

Fig. 2 Case 1. Left eye, showing gross marginal corneal thinning. Perforation occurred and the prolapsed iris was covered by operation with a conjunctival bridge flap.

Fig. 3 Case 1. Left cornea. The conjunctival flap has retracted leaving an area of dense scarring surrounding a central area of stromal regeneration. The corneal melting process is no longer active at this stage.

Fig. 4 Case 3. Right cornea at presentation, showing active scleritis, peripheral corneal thinning, and inflammatory cell infiltration.

Fig. 5 Case 3. Right cornea showing further progress in the degree of marginal ulceration.

Fig. 6 Case 4. Diffuse corneal thinning which first occurred 15 months after a cataract extraction. A central island of normal cornea is shown. 
of 1: 512 but tests for antinuclear factor and other autoantibodies were negative. $X$-ray of the hands showed typical rheumatoid changes.

For one year before presentation he had been seen in the ophthalmic clinic for progressive marginal thinning affecting the periphery of the lower half of each cornea. There was minimal associated inflammation in the sclera, and Schirmer's test showed some reduction of tear secretion, being $5 \mathrm{~mm}$ on each side.

He was treated with D-penicillamine $250 \mathrm{mg}$ a day for the first month, $500 \mathrm{mg}$ for the second month, and $750 \mathrm{mg}$ for the third month. By the end of 3 months the eye changes had improved dramatically. The left cornea showed little evidence of marginal thinning, and in the right eye re-epithelialization of the thinned areas was developing. At the same time the rheumatoid arthritis improved considerably.

\section{CASE 3}

In March 1976 this 73-year-old man developed a transient inflammatory polyarthritis affecting the PIP and MCP joints of both hands, and the MTP joints of both feet and both ankles. Plasma viscosity was raised at $1.90 \mathrm{cP}$ with a normal haemoglobin and white cell count. Rose-Waaler test was positive at a titre of $1: 128$; antinuclear factor and other autoantibody tests were negative. His arthritis persisted for several months. But by June 1976 there was little clinical evidence of joint disease.

In May 1976 he presented to the ophthalmic department with marginal thinning of the superior part of the right cornea. There was some associated vascularization and patchy inflammatory cell infiltration. In contrast to the 2 patients already described, there was an active scleritis adjacent to the corneal disease (Fig. 4). Tear secretion was reduced, Schirmer's test for the right eye being $4 \mathrm{~mm}$ and for the left $2 \mathrm{~mm}$. Rose bengal showed considerable punctate staining more marked on the right than on the left.

The corneal and scleral disease showed no response to intensive topical therapy with l-cysteine and steroid drops in either eye, and the marginal thinning progressed with increasing local inflammation (Fig. 5). At the same time the patient became generally unwell, with a leucocytosis and a productive cough. Examination showed the changes of chronic bronchitis and emphysema. Despite intensive investigations, no other cause for his illness was discovered, and his condition improved on antibiotic therapy.

Because of the progressive corneal change, he was

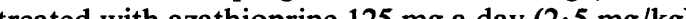

but after several weeks there was no evidence of arrest of the corneal thinning and scleritis. Sưbsequently he was again treated with topical coticosteroid drops (Guttae Betnesol) and this time showed a rapid improvement.

\section{CASE 4}

This 78-year-old man had a 12-year history of rheumatoid arthritis affecting the PIP and MCP joints in both hands, both wrists, shoulders, a円d feet with gross hallux valgus and MTP subluxation. He was not receiving any medication. Examination showed advanced but inactive disease. Plasia viscosity was raised at $2 \cdot 12 \mathrm{cP}$ with a haemoglobin of $11 \mathrm{~g} / \mathrm{dl}$ and white cell count of $5 \cdot 5 \times 10^{9} / 1$. RheuAatoid factor, antinuclear factor, and other aug antibody tests were negative. $X$-ray showed advandegd rheumatoid changes.

In December 1974 he had bilateral extractions ${ }_{\text {of }}$ senile cataracts without operative or postoperatize complications. In March 1976 he presented w wh bilateral corneal melting with marked margiriol guttering but no evidence of inflammatory changes (Fig. 6). On repeated observations the corneal melting was not progressive, and, in view of his age and general infirmity, positive therapv was net thought indicated. He is being followed up a frequent intervals.

\section{CASE 5}

This 82-year-old man was referred to the ophthaln $\rightarrow$ fc clinic with bilateral corneal thinning. Although had no rheumatic complaints examination did shov changes of trivial inactive polyarthritis affecting the MCP joints of both hands and both knees with rheumatoid nodules over both elbows. Plasina viscosity, haemoglobin, and white cell count we normal; rheumatoid factor, antinuclear factor, and other autoantibodies were absent.

The limbal guttering involved the whole of the periphery of each cornea, and in the right eye the was a marked degree of melting on the nasal side. There were many punctate inflammatory coll infiltrates in the stroma on each side and sompe episcleral hyperaemia on the nasa! side of the right ccrnea. He had previously shown an adverse response to topical steroid drops, in that they had apparently increased the melting process. Other loe therapy had not helped. In view of this, treatment with azathioprine $175 \mathrm{mg} /$ day $(2.5 \mathrm{mg} / \mathrm{kg})$ was introduced for a period of 2 months. Though the immediate clinical response was not dramatice, there was eventual improvement, with disappealance of the conjuctival hyperaemia and corneal infitunton 


\section{Discussion}

Damage to the cornea in rheumatoid arthritis may result from an adjacent scleritis with sclerosing keratitis-peripheral inflammatory cell infiltration and vascularization followed by permanent scarring-localized to the site nearest the inflamed sclera (McGavin et al., 1976). Limbal guttering occurs in association with rheumatoid scleritis, but may also develop in the apparent absence of scleral inflammation. It is possible that in some of these patients the scleritis was suppressed by local or systemic steroids. Patients may present with marginal thinning with no inflammatory changes except for a few dilated adjacent blood vessels (Watson, 1975). Occasionally the entire superficial part of the remaining central island of corneal stroma may slough away. Progressive melting away of the cornea may lead to perforation. If the anterior segment is replaced by grafting with homologous material, the graft may melt away in the same way (Brown and Grayson, 1968).

In patients with scleritis associated with rheumatoid arthritis the arthritis is usually severe with nodules and erosions with positive tests for rheumatoid factor and a low haemoglobin. Extra-articular manifestations of rheumatoid disease, particularly vasculitis, are common (Jayson and Jones, 1971). In contrast, the patients in this series showed a wide range of expression of rheumatoid disease, but in some, although there were advanced deformities, the arthritis was inactive without systemic manifestations and with negative tests for rheumatoid factor.

The relationship of keratolysis with Sjögren's syndrome is confused. Bloch et al. (1965) found a history of corneal ulceration in 3 of 63 patients with Sjögren's syndrome. Gudas et al. (1973) found one case, and Krachmer and Laibson (1974) recorded 6 patients with this combination. Some of the patients in the present series showed evidence of reduced lacrimal secretion but in none was tear production totally absent, whereas many patients with Sjögren's syndrome have much more severe limitation of tear formation without corneal ulceration. There are commonly other clinical manifestations of Sjögren's syndrome, such as xerostomia, but none was found in the present series. Moreover, a variety of autoantibodies are found in Sjögren's syndrome patients, but these tests were usually negative in the patients with keratolysis. Circulating antibodies to corneal tissue have been found in patients with idiopathic corneal ulceration-Mooren's ulcer (Schaap et al., 1969). Whether this is relevant to the corneal lesions in association with rheumatoid arthritis is uncertain.

Two types of pathological change have been described in patients with marginal guttering (Iwamoto et al., 1972). The first is inflammatory with marked vascularization in and around the corneal lesion and dilatation of the adjacent conjunctival blood vessels. Often these patients are treated with local steroid eye drops which reduce the inflammation, but the cornea continues to melt away. Electron microscopy of the cornea shows changes resembling hypersensitivity reactions with accumulation of lymphocytes, neutrophils, and oedema, and fibrinoid necrosis of small blood vessels. The second type is the so-called quiescent group, with much less vascularization and no evidence of inflammation. The electron microscopic appearances show fatty degenerative changes in the stroma. This description of the pathological changes must be compared with the classification of Aronson et al. (1970) who suggested that inflammatory diseases of the cornea could be separated into an infiltrative group secondary to some inflammatory process, and an ischaemic group which they divided into a primary subgroup which followed obstruction of blood vessels, possibly by deposition of immune complexes and intravascular clotting, and a secondary group following infection, trauma, or chemical damage.

There is now good evidence that whatever the cause, the melting of the cornea is mediated by collagenases. Berman et al. (1971) showed the production of collagenases in rabbit eyes, and subsequently (Berman et al., 1973a) in human material. These enzymes cleave the tropocollagen molecule into two components containing threequarters and one-quarter of the original molecule respectively. It seems that corneal fibroblasts can produce a proenzyme which is activated by lysosomal enzymes or trypsin to develop collagenolytic activity (Hook et al., 1973). This collagenase activity is inhibited by $\alpha-2$ macroglobulins with which they form complexes (Berman et al., 1975). It is of interest that some ophthalmolgists think that serum will inhibit corneal ulceration as $\alpha-2$ macroglobulins are present in serum (Berman et al., 1973b). $x-2$ macroglobulins are normally present in tears, perhaps explaining the association of marginal degeneration with reduced tear production and why the corneal ulceration was not relieved by the use of artificial tears. Berman et al. (1973b) experimentally found a relationship between $\alpha-2$ macroglobulin activity in tears and the extent of corneal ulcers.

With regard to treatment of corneal ulceration, the evidence is confused by the failure to examine separately corneal ulceration of different causes. Hook et al. (1973) thought that local steroids would potentiate collagenolytic activity, so promoting keratolysis. Several of the patients in the present series had received steroids systemically and 
locally, and it is not possible to know whether this produced or exacerbated the corneal disease or whether it was simply the patients with most severe disease who were receiving more aggressive forms of therapy. It is our impression that topical steroids had a deleterious effect in one patient and are contraindicated over a long period. However, in one patient improvement only occurred with local steroid therapy. Understanding of the part played by collagenases in the pathogenesis of corneal melting has led to trials of cysteine, acetylcysteine, and penicillamine drops locally (Slansky and Dohlman, 1970; Francois et al., 1973; Mehra and Singh, 1975) as they are thought to inhibit collagenase activity. Although these agents seem effective in experimental trials, they proved disappointing in the present study. Elliott et al. (1972) proposed the use of local heparin for peripheral corneal ischaemic lesions. In the one patient who received this treatment, we found it of no value. In any event, on theoretical grounds it seems unlikely to help. A further form of therapy is to apply contact lenses which protect the ulcerated area and act as an artificial epithelium. They may lead to healing of the defect beneath.

Operative measures may not be successful. It is well known that peripheral ulceration can recur in patients who have cornea scleral replacements (Watson, 1975), and in addition an enhanced rejection of donor tissue has been noted. Attempts have also been made to cover corneal perforations with conjunctival flaps or scleral autografts, but the results have not been encouraging. Many such procedures result in visual loss. However, a report of good healing in several types of progressive marginal ulceration after excision and recession of adjacent limbal conjunctiva has recently appeared (Wilson et al., 1976). We feel that iris prolapse is not necessarily an indication for surgery, as a thin layer of corneal tissue can reform over the knuckle of iris and afford protection against pathogenic microorganisms.

We found 3 patients with progressive disease which came under control only when systemic therapy was started with azathioprine or penicillamine. In one patient with scleritis and corneal ulceration there was no response to azathioprine. In any uncontrolled small series of this type it is impossible to draw valid conclusions, but we suggest that with incipient or repeated perforation of the cornea it is worth trying these agents.

\section{References}

Aronson, S. B., Elliott, J. H., Moore, T. E., Jr., and O'Day, D. M. (1970). Pathogenetic approach to therapy of peripheral corneal inflammatory disease. American Journal of Ophthalmology, 70, 65-90.
Berman, M., Dohlman, C. H., Gnädinger, M., and Davisqn P. (1971). Characterisation of collagenolytic activity in the ulcerating cornea. Experimental Eye Research, 11, 255-257. Berman, M. B., Kerza-Kwiatecki, A. P., and Davisō, P. F. (1973a). Characterisation of human corneal coflagenase. Experimental Eye Research, 15, 367-373.

Berman, M. B., Barber, J. C., Talamo, R. C., and Langle C. E. (1973b). Corneal ulceration and the serum anffproteases. I. $\alpha_{1}$-antitrypsin. Investigative Ophthalmologi, 12, 759-770.

Berman, M., Gordon, J., Garcia, L. A., and Gage, J. (1975ी). Corneal ulceration and the serum antiproteases. II. Com plexes of human corneal collagenases and $\alpha$-macroglobulins. Experimental Eye Research, 20, 231-244.

Bloch, K. J., Buchanan, W. W., Wohl, M. J., and Bunif J. J. (1965). Sjögren's syndrome. A clinical, pathologiggl and serological study of sixty-two cases. Medicine, 4 , 187-231.

Brown, S. I., and Grayson, M. (1968). Marginal furrow. A characteristic corneal lesion of rheumatoid arthritis. Archives of Ophthalmology, 79, 563-567.

Elliott, J. H., Aronson, S. B., Moore, T. E., and Williarf?, F. C. (1972). Heparin therapy of peripheral corngl ischemic syndromes. Symposium on the Cornea (Transactions of the New Orleans Academy of Ophthalmology, pp. 78-104. Ed. by R. Castroviejo. Mosby, St. Louis.

Francois, J., Cambie, E., Feher, J., and Van den Eeeckhogi, E. (1973). Collagenase inhibitors (penicillamine). Ann ब्व $s$ of Ophthalmology (Chicago), 5, 391-408.

Gudas, P. P., Jr., Altman, P., Nicholson, D. H., and Greé?, W. R. (1973). Corneal perforations in Sjögren syndrome. Archives of Ophthalmology, 90, 470-472.

Hook, R. M., Hook, C. W., and Brown, S. I. (1973). Fibioblast collagenase; partial purification and characterisatio Investigative Ophthalmology, 12, 771-776.

Iwamoto, T., De Voe, A. G., and Farris, R. L. (1972). Electron microscopy in cases of marginal degeneration the cornea. Investigative Ophthalmology, 11, 241-257.

Jayson, M. I. V., and Jones, D. E. P. (1971). Scleritis a $\overrightarrow{\overline{\mathrm{d}}}$ rheumatoid arthritis. Annals of the Rheumatic Diseas, 30, 343-347.

Krachmer, J. H., and Laibson, P. R. (1974). Corneal thinn 莺g and perforation in Sjögren's syndrome. American Jourinal of Ophthalmology, 78, 917-920.

McGavin, D. D. M., Williamson, J., Forrester, J. B., Foul W. S., Buchanan, W. W., Dick, W. C., Lee, P., MacSweę, R. N. M., and Whaley, K. (1976). Episcleritis and scleritts. A study of their clinical manifestations in association with rheumatoid arthritis. British Journal of Ophthalmology, 60, 192-226.

Mehra, K. S., and Singh, R. (1975). Cysteine in cornęl ulcer. I. An experimental study. Annals of Ophthalmology, 7, 1329-1331.

Schaap, O. L, Feltkamp, T. E. W., and Breebaart, A. (1969). Circulating antibodies to corneal tissue in a pstieft suffering from Mooren's ulcer (ulcus rodens corneae). Clinical and Experimental Immunology, 5, 365-370.

Slansky, H. H., and Dolhman, C. H. (1970). Collagenase and the cornea. Survey of Ophthalmology, 14, 402-416.

Watson, P. G. (1975). Connective tissue disorders and $\bar{h}$ eye. Recent Advances in Ophthalmology, pp. 214-200. Ed. by P. D. Trevor-Roper. Churchill Livingstow, Edinburgh and London.

Watson, P. G. and Hayreh, S. S. (1976). Scleritis and episcleritis. British Journal of Ophthalmology, 60, 163-194.

Wilson, F. M., Grayson, M., and Ellis, F. D. (1976). Tre ment of peripheral corneal ulcers by limbal conjungisvectomy. British Journal of Ophthalmology, 60, 713-719 